\title{
A inserção do conjunto CFESS/CRESS nos conselhos de políticas e de direitos*
}

IVANETE BOSCHETTI*

Rosa Helena Stein ${ }^{* * *}$

Resumo: O artigo reflete sobre a inserção do Conjunto CFESS/ CRESS nos conselhos de políticas e de direitos entendidos como espaços importantes de participação política e exercício de controle popular sobre o Estado. A experiência concreta de mobilização e intervenção nesses espaços, desde os anos 1990, permite fazer um balanço de suas possibilidades e limites no processo democrático de transformação social tendo como parâmetro o projeto ético-político-profissional do assistente social.

Palavras-chave: conjunto CFESS/CRESS, conselhos, transformação societária.

* Texto elaborado a partir de levantamento efetuado junto aos CRESS e, originalmente, apresentado no $35^{\circ}$ Encontro Nacional CFESS/CRESS, ocorrido em Vitória/ES, em setembro de 2006, na mesa intitulada Conselhos de Políticas e de Direitos: Potencialidades de Transformação Social.

O texto, ampliado, foi apresentado no Encontro Estadual: A participação dos Assistentes Sociais nos Conselhos de Direitos e de Política, realizado no Rio de Janeiro, em 10 de agosto de 2007, e publicado na revista Em Foco (número 4, agosto, 2008).

** Assistente Social, mestre em Política Social, doutora em Sociologia, professora do Departamento de Serviço Social da UnB, conselheira vice-presidente do CFESS na gestão 2005-2008 e conselheira presidente na gestão 2008-2011.

${ }^{* * *}$ Assistente Social, mestre em Política Social, doutora em Sociologia, professora do Departamento de Serviço Social da UnB, conselheira tesoureira do CFESS nas gestões 2005-2008 e 2008-2011. 
The Insertion of the CFESS/CRESS Block in the Policies and Rights Councils

\begin{abstract}
The article is about the insertion of the CFESS/ CRESS Block in the Policies and Rights Councils considered as important spaces of political participation and also of popular control over the State. The concrete experience of mobilization and intervention in these spaces since the 1990's results in the analysis of its possibilities and limits in the democratic process of social transformation taking, as a parameter, the ethical, political and professional project.
\end{abstract}

Keywords: CFESS/CRESS block, councils, societal transformation.

\title{
Questão social e transformação societária
}

É impossível discutir a potencialidade de transformação social em sua relação com o papel dos conselhos de políticas e de direitos sem mencionar e qualificar o sentido de transformação social aqui abordado. Quando pensamos em transformação radical da sociedade capitalista, no sentido de superação e enfrentamento da questão social, é certo que, desde logo, se evidenciam os limites de os conselhos se constituírem em um espaço de possibilidade de exercício dessa transformação. Não é excessivo lembrar que o enfrentamento da questão social implica a transformação radical da sociedade capitalista no sentido de superar sua fundamental determinação, assentada na apropriação privada da riqueza socialmente produzida. Obviamente, assumimos aqui a perspectiva de que não existe uma nova questão social, nos termos defendidos por Rosanvallon (1995) ou ainda por Castel (1995), embora a perspectiva deste seja bastante diferente daquela defendida por Rosanvallon. Compreendemos a questão social como fenômeno próprio da sociedade capitalista, determinada, do ponto de vista econômico, pela expropriação privada da produção coletiva, nos termos de Marx (1982). 
Nessa perspectiva, a superação da questão social só é possível por meio de uma radical transformação societária que não prescinde da socialização da riqueza e de suas formas de produção. Portanto, requer muito mais do que o investimento na socialização da política, pelas vias da intervenção em conselhos e espaços institucionais de gestão de políticas públicas, embora esses sejam espaços importantes de socialização da política.

O enfrentamento da questão social na perspectiva de sua radical transformação foi conduzida pela classe trabalhadora no final do século XIX e início do século $X X$ com diversas formas de lutas emancipatórias que tinham como horizonte a superação da ordem capitalista e a instituição de uma sociedade baseada na socialização dos meios de produção. Desde meados do século XX, contudo, prevalecem alianças entre capital e trabalho que conduzem a reformas sociais e reconhecimento parcial de direitos civis, políticos e sociais como "caminhos" para a construção da cidadania (Marshal, 1967), tendo a perspectiva da emancipação econômica, política e social ficado subsumida. O Estado democrático capitalista foi obrigado a reconhecer, incorporar e institucionalizar demandas da classe trabalhadora e se travestiu em Estado social nos países capitalistas centrais, expressando o resultado de reformas sociais decorrentes das lutas e pressões da classe trabalhadora (Behring e Boschetti, 2007).

A experiência histórica que levou à instituição do Welfare State no países da Europa ocidental e à expansão das políticas sociais em praticamente todos os países capitalistas foi, seguramente, determinada pela conjunção de políticas regulatórias fordistas-keynesianas com alianças de classe. Tais elementos permitiram certa redução das desigualdades 
sociais, mas não extinguiram a exploração de classe, não instituíram igualdade de condições e nem asseguraram a emancipação econômica e política da classe trabalhadora, que continua sendo obrigada a vender sua força de trabalho para assegurar as condições básicas de vida e sobrevivência. As transformações societárias ocorridas no século XX, assim, permitiram largamente a expansão dos direitos e ampliação do acesso da classe trabalhadora aos bens de consumo e aos espaços de socialização da política, mas não foram capazes de apresentar "soluções" para a questão social.

\section{Redemocratização e perspectiva de ampliação dos espaços de socialização da política e acesso aos direitos no Brasil}

No Brasil, a década de 1930 marcou a emergência de sistemas nacionais públicos de política social, que sempre foram associados ao mercado: previdência, saúde, educação, emprego (Boschetti, 2006). Em seu processo histórico de expansão e consolidação, esses sistemas instituíram direitos limitados e restritos. Nunca foram universais, seja pela baixa qualidade dos serviços (saúde e educação básica), pelo caráter meritocrático (previdência e ensino superior), clientelista (assistência social) ou, ainda, pela política econômica orientada pela rentabilidade e acumulação, pouco dedicada à geração de emprego e renda para todos. Os movimentos sociais brasileiros viveram e enfrentaram a perversa relação de repressão e cooptação, nos longos períodos autoritários e nos curtos períodos democráticos.

A Constituição Federal de 1988 é, portanto, um marco na instituição da democracia representativa e respondeu ao clamor da democracia participativa ao prever a expansão dos direitos e políticas sociais e a possibilidade de criação de espaços de participação e controle democrático da sociedade, 
como os conselhos, conferências e fóruns de políticas sociais. Esse movimento, contudo, aconteceu já em contexto mundial de avanço do neoliberalismo (Navarro, 1998; Anderson, 1995) e as políticas sociais sofreram profundo processo de reorganização, combinando descentralização, participação e controle social com tendências privatistas e contra-reformas de cunho neoliberal (Behring, 2001, 2003). Os conselhos e conferências figuram cada vez mais como importante espaço de possibilidade de participação política e exercício de controle popular sobre o Estado, historicamente autoritário e prebendalista. Sua instituição e expansão mobilizaram a participação de entidades da sociedade civil e canalizaram o movimento e anseio de participação cidadã. Ocorreu intenso processo de envolvimento de entidades representativas de trabalhadores, usuários, prestadores de serviços privados e do Estado na constituição, organização e funcionamento de conselhos em todas as esferas de governo e no âmbito de, praticamente, todas as políticas sociais.

Hoje, além de conselhos organizados em torno das políticas sociais, temos conselhos por segmentos (mulher, pessoa idosa, pessoa com deficiência, comunidade negra), ou temáticos (comunidade, execuções penais, assuntos penitenciários). Inegavelmente, os conselhos, conferências e fóruns constituem, desde o final do século passado, um importante espaço de intervenção profissional e exercício democrático de formulação, discussão, debate e construção de princípios e diretrizes para as políticas e os direitos sociais, contudo, ao comemorarmos 20 anos da Constituição Federal, o reconhecimento de sua importância e significado não deve nos eximir de problematizar suas possibilidades na perspectiva da transformação societária. 


\section{Participação do conjunto CFESS/CRESS em conselhos, fóruns e comitês}

Temos hoje a experiência concreta de mobilização e intervenção nesses espaços, o que nos permite fazer um balanço de suas possibilidades e limites no processo democrático de transformação social no sentido de se construir uma intervenção qualificada e solidamente ancorada no exercício da necessária radicalidade democrática. Essa compreensão é de tal forma reconhecida e assumida pelo conjunto CFESS/CRESS como uma forma de mediar a materialização de nosso projeto éticopolítico profissional que temos ampliado nossa participação em conselhos e fóruns.

No âmbito nacional, desde a década de 1990, o Conselho Federal de Serviço Social (CFESS) vem assumindo a representação em diversos conselhos e fóruns. Atualmente, - CFESS possui representação titular no Conselho Nacional de Saúde (CNS), no Conselho Nacional dos Direitos do Idoso (CNI) e no Conselho Nacional das Profissões Regulamentadas. $\mathrm{Na}$ condição de suplente, participa do Conselho Nacional dos Direitos da Criança e do Adolescente (CONANDA) e do Conselho Nacional de Assistência Social (CNAS), além de acompanhar o desenvolvimento e atuação de outros, como o Conselho Nacional dos Direitos da Pessoa Portadora de Deficiência (Conade), o Conselho Nacional de Segurança Alimentar e Nutricional (Consea), o Conselho Nacional de Previdência Social (CNPS), o Conselho Nacional dos Direitos da Mulher (CNDM) e o Conselho das Cidades (ConCidades).

O CFESS também participa ativamente de diversos fóruns de articulação da sociedade civil, como o Fórum Brasil de Orçamento (FBO), Fórum Nacional de Assistência Social (FNAS), o Fórum de Entidades Nacionais de Trabalhadores da Área da Saúde (Fentas), e o Fórum em Defesa dos Direitos da Criança e Adolescente (Fórum DCA). 


\section{Tabela 1 - Representação em conselhos de políticas e de direitos por CRESS/2006}

\begin{tabular}{|c|c|c|}
\hline $\begin{array}{l}\text { CRESS } \\
\text { Seccional }\end{array}$ & Natureza dos Conselhos & № \\
\hline 1a/PA & CEPI, CEAS, CMAS, Comunidade de Execuções Penais & 05 \\
\hline 2ª/MA & CMCondição Feminina, CEDCA, CEAS & 03 \\
\hline 3a/CE & CEAS, CMAS, COMDICA & 03 \\
\hline 4a/PE & CEAS, CMAS, Conselho Curador da UFPE & 13 \\
\hline 5 a/BA & CMS, CES, CEAS & 03 \\
\hline 6ª/MG & $\begin{array}{l}\text { CEPI, CEAS, CMAS, CEDPPD, CES, CMHabitação, } \\
\text { CMEducação, Defesa Civil, Comunidade, CMS }\end{array}$ & 21 \\
\hline $7 \stackrel{a}{a} / \mathrm{RJ}$ & $\begin{array}{l}\text { CMPI, CEAS, CMAS, Antidrogas, COMDICA, CMS, Direitos da } \\
\text { Mulher, CONSEAS, CMDPPD }\end{array}$ & 42 \\
\hline 8 $/ \mathrm{DF}$ & CAS/DF, DH, Avaliação do Programa Renda Minha & 03 \\
\hline 9aㅅP & $\begin{array}{l}\text { COMDICA, CMAS, CMDPPD, CMPI, Conselho da Comunidade, } \\
\text { Comunidade Negra, Direitos da Mulher, CMC, CMS, CONSEAS, } \\
\text { Moradia Popular, Reforma Psiquiátrica, Bolsa Família, } \\
\text { Antidrogas, CEAS }\end{array}$ & 40 \\
\hline $10^{\mathrm{a}} / \mathrm{RS}$ & $\begin{array}{l}\text { CEAS, CES, CEHab., CMAS, CMDCA, CMS, CMI, CMS, } \\
\text { CMDPDef }\end{array}$ & 61 \\
\hline $11 \stackrel{a}{a} / \mathrm{PR}$ & $\begin{array}{l}\text { CES, CEAntidrogas, CEDI, CEAS, CMAS, COMDICA, CMSM, } \\
\text { CMS, Conselho Municipal da Mulher, CMAntidrogas, Conselho } \\
\text { Local de Hospital, Conselho da Comunidade }\end{array}$ & 26 \\
\hline $12^{\mathrm{a}} / \mathrm{SC}$ & $\begin{array}{l}\text { CES, CEI, CESAN, CMAS, CMI, CMDCA, Comunidade, } \\
\text { Conen }\end{array}$ & 11 \\
\hline $13^{\mathrm{a}} / \mathrm{PB}$ & CEAS, CMAS, COMSEAS & 03 \\
\hline $14 \stackrel{a}{a} / \mathrm{RN}$ & CMAS, CES, CONESAM, CEPI, Conselho da Comunidade PJ & 07 \\
\hline $15^{\mathrm{a}} / \mathrm{AM} / \mathrm{RR}$ & CEAS, CES, CMAS, COMDICA & 04 \\
\hline 16 a $/ A L$ & $\begin{array}{l}\text { CEAS, CES, CEldoso, CESegurançaAlimentar, CEDCA, CMAS, } \\
\text { CMS, CMHabitação }\end{array}$ & 08 \\
\hline $17^{\mathrm{a}} / \mathrm{ES}$ & CEDPPD, CEAS, COMDICA & 03 \\
\hline $18^{\mathrm{a}} / \mathrm{SE}$ & CEAS, CMAS, CMS, COMDICA & 04 \\
\hline 19/GO e TO & $\begin{array}{l}\text { CEAS, CMAS, CMS, CES, CEPI, Conselho Penitenciário, } \\
\text { Comunidade, CEDCA,, Habitação }\end{array}$ & 12 \\
\hline 20/MT & $\begin{array}{l}\text { CEAS, CES, CEDMulher, CEDCA, CEAntiDrogas, CMAS, CMS, } \\
\text { CMHab, CMDCA, CComunidade }\end{array}$ & 27 \\
\hline $21 \stackrel{\mathrm{a}}{\mathrm{MS}}$ & CMAS & 01 \\
\hline $22^{\mathrm{a}} / \mathrm{PI}$ & CEDCA, CMAS, CEAS, CES, CMS & 05 \\
\hline 23응/AC & $\begin{array}{l}\text { CEAS, CMAS, CEDCA, COMDICA, CES, Conselho da } \\
\text { Comunidade, CEAP }\end{array}$ & 07 \\
\hline 24ㄴaP & CEAS, CMAS, CES, CMS, CEDCA, CESA & 07 \\
\hline \multicolumn{2}{|l|}{ TOTAL } & 318 \\
\hline
\end{tabular}


No âmbito de Estados e municípios, os Conselhos Regionais de Serviço Social (CRESS) também têm uma participação ativa em conselhos e fóruns. Levantamento efetuado no final de 2006 em 25 CRESS e Seccionais revelou que estes possuem representação em 318 conselhos, sendo 72 em âmbito estadual e 246 em âmbito municipal. Juntos, os CRESS do Rio de Janeiro, São Paulo, Minas Gerais, Paraná e Rio Grande do Sul apresentam representação em 190 conselhos, o que significa $59,75 \%$ do total. Além dos conselhos, os CRESS ainda participam de diversos fóruns e comitês. A Tabela 1 indica a presença e intensidade da participação dos CRESS em mais de um conselho.

Os mesmos dados, apresentados agora com foco no tipo e âmbito do conselho, demonstram, por um lado, a diversidade da representação, e por outro, indicam que a Política de Assistência Social, seguida pela de Saúde, são os principais campos de representação dos CRESS. A Tabela 2 também revela que as representações dos CRESS não são exercidas apenas por conselheiros/as da diretoria, mas contam com significativa colaboração de assistentes sociais de base.

Além da representação em cnselhos, os CRESS participam em diversos fóruns, comitê e comissões, conforme abaixo:

\section{Fóruns}

- dos Conselhos de Saúde

- de Assistência Social

- de Saúde Mental

- de Mulheres

- do Idoso

- dos Direitos da Criança e do Adolescente

- Estadual da Reforma Urbana 


\section{Tabela 2 - Representação dos CRESS por natureza e âmbito do conselho e quem representa - 2006}

\begin{tabular}{|c|c|c|c|c|}
\hline Natureza do & Âmbito do & \multicolumn{3}{|c|}{ Quem representa o CRESS* } \\
\hline Conselhos & $\begin{array}{l}\text { Conselho } \\
\text { Estadual }\end{array}$ & $\begin{array}{l}\text { Conselho } \\
\text { Municipal }\end{array}$ & $\begin{array}{l}\text { Conse- } \\
\text { Iheiro/a }\end{array}$ & $\begin{array}{c}\text { Assistente } \\
\text { Social } \\
\text { de Base }\end{array}$ \\
\hline 1. Assistência Social & 27 & 131 & 32 & 54 \\
\hline 2. Saúde & 15 & 34 & 06 & 18 \\
\hline $\begin{array}{l}\text { 3. Criança/ } \\
\text { Adolescente }\end{array}$ & 09 & 27 & 04 & 20 \\
\hline 4. Pessoa Idosa & 06 & 08 & - & 08 \\
\hline 5. Comunidade & - & 18 & 04 & 07 \\
\hline $\begin{array}{l}\text { 6. Pessoa com } \\
\text { Deficiência }\end{array}$ & 02 & 05 & 03 & 03 \\
\hline $\begin{array}{l}\text { 7. Segurança } \\
\text { Alimentar }\end{array}$ & 06 & 02 & 04 & 02 \\
\hline 8. Antidrogas & 01 & 06 & 01 & 04 \\
\hline 9. Direitos da Mulher & 01 & 06 & - & 06 \\
\hline 10. Direitos Humanos & 02 & - & - & 02 \\
\hline $\begin{array}{l}\text { 11. Habitação, } \\
\text { Moradia Popular }\end{array}$ & 01 & 02 & 01 & - \\
\hline 12. Educação & - & 04 & - & - \\
\hline $\begin{array}{l}\text { 13. Programa Renda } \\
\text { Minha }\end{array}$ & 01 & - & 01 & - \\
\hline 14. Bolsa-Família & & 01 & & \\
\hline $\begin{array}{l}\text { 15. Comunidade } \\
\text { Negra }\end{array}$ & - & 01 & - & 01 \\
\hline 16. Defesa Civil & - & 01 & - & -0 \\
\hline $\begin{array}{l}\text { 17. Conselho } \\
\text { Penitenciário }\end{array}$ & 01 & & & 01 \\
\hline Total & 72 & 246 & 56 & 125 \\
\hline
\end{tabular}

* Nota: O número de representantes é inferior ao número de conselhos pois a mesma pessoa pode estar em mais de um conselho 
- Meio Ambiente e Desenvolvimento Sustentável

- Permanente de Direitos Humanos

- Permanente de Defesa dos Direitos do Deficiente

- Permanente de Prevenção ao Uso Indevido de Drogas (Previda)

- Segurança Alimentar

- Permanente da Região Sul (PNI)

- Estadual em Prol da Educação Inclusiva

- Estadual pela Erradicação do Trabalho Escravo

Comissões, Comitês e Associações

- Comissão Municipal de Reforma Psiquiátrica

- Comissão Municipal de Saúde Mental

- Comissão Interinstitucional de Defesa dos Direitos dos Adolescentes Privados de Liberdade

- Comissão Interinstitucional de Enfrentamento à Violência Infanto-Juvenil

- Comissão Interinstitucional de Saúde do TrabaIhador

- Comissão de Erradicação do Trabalho Infantil

- Comissão Judiciária de Adoção

- Comissão Estadual DST/HIV/Aids

- Comissão Estadual Judiciária de Adoção

- Comissão de Saúde da Mulher

- Comitê Popular de Combate e Erradicação do Trabalho Escravo

- Comissão de Assistência Social da OAB/SC 
- Comitê de Defesa dos Direitos Humanos

- Comitê de Controle Social do Programa BolsaFamília

- Comitê Temático de Desenvolvimento Regional

- Colegiado do Curso de Serviço Social (universidade)

- Conselho Curador - órgão deliberativo (universidade)

- Câmara Técnica DST/Aids e Cidadania

- Associação Conselhos Profissionais (Ascop)

- Pólo Locorregional Litoral/Centro de Educação Permanente do SUS

- Associação de Assistentes Sociais de Joinville

- Associação dos Conselhos Profissionais de Santa Catarina

A diversidade na representação aponta a riqueza de atuação dos conselhos regionais na defesa dos direitos e políticas sociais e seu investimento na participação democrática e no controle social popular. Essa experiência, entretanto, não é isenta de contradições. Se, por um lado, fortalece a socialização da política, por outro, revela os limites dos conselhos no processo de transformação social e aponta as dificuldades do exercício democrático coletivo numa perspectiva de totalidade, conforme apontaram os CRESS.

\section{Dificuldades apontadas pelos CRESS no exercício da representação}

No levantamento efetuado em 2006, apenas cinco CRESS indicaram que não enfrentam dificuldades no exercício da representação nos Conselhos. Os demais apontaram 
diversas dificuldades, que foram agrupadas de acordo com sua natureza.

\section{Dificuldades relativas às condições dos CRESS}

- Disponibilidade dos conselheiros e compatibilização da agenda das representações com os compromissos decorrentes da representação, agenda do CRESS e trabalho profissional;

- Limitação por parte dos conselheiros em compreender o papel e importância dos conselhos e a sua inserção;

- Garantia de recursos financeiros da receita do CRESS para manter a presença das representações em todas as atividades;

- Domínio do marco legal da área representada pelo conselheiro;

- Dificuldade para manter as representações municiadas das principais questões atuais do debate em cada área e, ao mesmo tempo, socializar as discussões para a categoria e também entre o CFESS e o Regional;

- Não existência de liberação de horário de trabalho para participação em eventos de capacitação e/ou de troca de experiências;

- Reduzida participação de assistentes sociais que representam o CRESS nos Conselhos nos eventos realizados pelo CRESS para debates sobre o controle social (bem como em outras ações promovidas pela entidade); a presença de estudantes e profissionais interessados no tema é bastante significativa, mas a participação não se reflete em representação efetiva nos conselhos; 
- Dificuldade em receber relatórios periódicos dos representantes dos CRESS sobre sua participação nos Conselhos;

- Dificuldade de escolha de representações no tempo solicitado pelos conselhos, em geral, muito exíguo;

- Concentração de atividades em poucos assistentes sociais de base que participam das ações dos CRESS

- Falta de relação mais próxima dos CRESS com os representantes do CFESS nos conselhos e fóruns nacionais, o que retarda a socialização de informações e documentos para os CRESS e dificulta o debate de temas como PNAS, NOB-SUAS, NOB-RH, SUAS/ WEB, PSF, entre outras;

- Falta de espaços de debates dos temas nacionais ligados à assistência social no conjunto CFESS/ CRESS;

- Dificuldade de articulação do CRESS com as representações assumidas nos municípios do interior do Estado, devido à distância das sedes (CRESS e Seccional);

- Descontinuidade da representação pelo profissional (sobretudo da base), que muitas vezes não realiza o trâmite da substituição, perdendo ou deixando o assento vago, o que fragiliza a credibilidade dos CRESS;

- Dificuldade de planejar a representação, de modo a garantir orçamento para os custos da participação, capacitação e acompanhamento;

- Dificuldade de articulação com outros sujeitos/entidades que defendem os mesmos princípios do conjunto CFESS/CRESS nos espaços dos Conselhos. 
Dificuldades próprias dos conselhos de direitos e de política social

a) Dificuldades de natureza política

- Conselhos não têm reconhecimento governamental, ocasionando descaso e desrespeito pelas suas decisões;

- Presença dos conselheiros de raiz religiosa tende a afastar os conselhos dos seus objetivos;

- Representação exercida de forma individual, alheia à compreensão de que a representação é da entidade de classe, e deve ser orientada por princípios e interesses éticos coletivos;

- Dificuldade no acesso às informações necessárias para que o controle possa ser efetivado;

- Dificuldade de articulação política entre as entidades da sociedade civil;

- Encaminhamento de interesses corporativos (instituições defendendo seus próprios projetos), sem um debate mais aprofundado sobre as políticas sociais;

- Reuniões dedicadas excessivamente para análise e aprovação de convênios e financiamentos a entidades, deixando de apreciar a direção dada às políticas sociais (esta característica está especialmente presente nos conselhos de âmbito municipal, particularmente nos conselhos de assistência social);

- Há conselhos que não comunicam ao CRESS a existência de vagas para a representação da entidade;

- Dificuldade dos conselheiros compreenderem e defenderem a política pública como direito do cidadão 
ante o predomínio do estereótipo de que os usuários são negligentes;

- Dificuldade em manter a autonomia da sociedade civil e fazer com que a representação não-governamental se apodere das discussões e não seja fortemente influenciada pela representação governamental;

- Ausência de capacitação, principalmente dos conteúdos referentes ao acompanhamento financeiro de programas e projetos;

- Falta de conhecimento da realidade por parte dos conselheiros, pois inexiste um mapeamento da situação local para a compreensão das reais necessidades relativas à política a ser formulada no âmbito de cada Conselho;

- Ausência de plano de ação para a gestão dos conselhos;

- Desconhecimento do orçamento público pelos conselheiros.

b) Dificuldades relacionadas à infra-estrutura e organização dos conselhos de direitos e de políticas sociais

- Escassez de recursos para funcionamento regular (papel, cartucho de tinta, etc);

- Ausência de objetividade durante as reuniões (pautas muito longas, atrasos no início e, conseqüentemente, na finalização das reuniões, etc.);

- Dificuldade na estrutura física dos conselhos, como garantia de transporte para conselheiros em visitas institucionais;

- Ausência de ajuda de custo aos conselheiros nãogovernamentais em viagem para atividades dos conselhos. 


\section{Para finalizar: limites das representações na perspectiva da transformação}

Muitas das dificuldades vivenciadas pelo conjunto CFESS/CRESS no exercício da representação nos conselhos de direitos e políticas sociais estão diretamente ligadas à própria estrutura e características centrais dos conselhos: espaço plural de representação de diversos interesses, onde os do Estado e da sociedade nem sempre tem caráter paritário.

Os conselhos têm contribuído para fazer avançar o processo democrático, mas não podemos negar também que seu processo de constituição e desenvolvimento tem contribuído para a institucionalização dos conflitos e demandas, antes canalizados para manifestações e reivindicações de massa. São espaços que, cada vez mais proliferam e se diversificam, o que contribui para a fragmentação das demandas e das respostas públicas. Os direitos, muitas vezes, não são defendidos como direitos dos cidadãos, mas como direitos específicos de determinado segmento: dos idosos, das pessoas com deficiência, da mulher... sem uma necessária relação entre as necessidades e demandas particulares e o reconhecimento geral dos direitos de todos/as. Os conselhos têm favorecido, também, a representação corporativa de interesses específicos, que vão desde a defesa de interesses empresariais até interesses corporativos profissionais. Nesse sentido expressam mais interesses específicos e menos interesses de classe.

São espaços de democracia representativa, mas com limitada participação direta. Os processos eleitorais, muitas vezes, são organizados de modo a feudalizar e eleger grupos e/ou composições pré-definidos.

Evidentemente que o reconhecimento destas dificuldades e limites não subtrai importância dos conselhos, pois constituem 
importantes espaços de tencionamento das demandas e relações sociais, de acesso à informação, de acompanhamento das políticas públicas, de articulação entre forças sociais convergentes, de divulgação e socialização de nossas posições, e de defesa ampla de direitos e políticas. Mas não devemos abrir mão de perguntar e avaliar permanentemente até que ponto os Conselhos têm conseguido se firmar como trincheira de resistência à políticas neoliberais que reduzem direitos, e como espaço de luta para ampliação de direitos.

Tendo em vista o papel dos movimentos sociais nas históricas lutas de transformação societária, mais do que nunca devemos investir no fortalecimento dos movimentos sociais autônomos e dos conselhos visando atuar na perspectiva da radicalidade democrática, o que pressupõe:

- estimular a participação mais efetiva dos movimentos sociais dos trabalhadores nos conselhos, de modo a tencioná-los e forçar a defesa de direitos universais;

- não canalizar todas as perspectivas de luta para os conselhos, visto que não são espaços substitutos dos movimentos sociais;

- ficar atentos e vigilantes para que a atuação nos conselhos não despotencialize as lutas políticas mais gerais e ofensivas da classe trabalhadora;

- lutar para que os conselhos não atuem no espaço restrito da institucionalidade estatal.

Nossa atuação nos conselhos, inegavelmente, é uma contribuição à construção dos espaços democráticos, e deve ser parametrada pelo projeto ético-político-profissional no sentido de compreendê-la como uma mediação necessária e importante para a socialização da política. Esta, contudo, não deve se sobrepor ao necessário e imprescindível fortalecimento 
dos movimentos sociais, como sujeitos coletivos capazes de potencializar as lutas necessárias à transformação radical da sociedade capitalista.

\section{Referências bibliográficas}

ANDERSON, Perry. Balanço do neoliberalismo. In: SADER, E.; GENTILI, P. (orgs.). Pós-neoliberalismo: as políticas sociais e o Estado democrático. Rio de Janeiro: Paz e Terra, 1995.

BEHRING, Elaine. Os Conselhos de Assistência Social e a construção da democracia. Cadernos ABONG, São Paulo, v. 30, p. 93-116, nov. 2001.

Brasil em contra-reforma: desestruturação do Estado e perda de direitos. São Paulo: Cortez, 2003.

BEHRING, Elaine; BOSCHETTI, Ivanete. Política social: fundamentos e história. 2.ed. São Paulo: Cortez, 2007.

BOSCHETTI, Ivanete. Seguridade social e trabalho: paradoxos na construção das políticas de previdência e assistência social. Brasília: Letras Livres, Ed. da UnB, 2006.

CASTEL, Robert. Les métamorphoses de la question sociale: une chronique du salariat. Paris: Fayard, 1995.

MARX, K. Introdução à crítica da economia política. In: MARX, K. Para a crítica da economia política. São Paulo: Abril Cultural, 1982. (Col. Os Economistas).

MARSHALL, T. H. Cidadania, classe social e status. Rio de Janeiro: Zahar, 1967.

NAVARRO, V. Neoliberalismo y Estado del bienestar. 2. ed. Barcelona: Ariel, 1998.

ROSANVALLON, Pierre. La nouvelle question sociale: repenser l'Etatprovidence. Paris: Éditions du Seuil, 1995. 